\title{
The management and outcome of paediatric splenic injuries in the Netherlands
}

\author{
Maike Grootenhaar ${ }^{1} \mathbb{D}$, Dominique Lamers ${ }^{2}$, Karin Kamphuis-van Ulzen ${ }^{3}$, Ivo de Blaauw ${ }^{4}$ and Edward C. $\operatorname{Tan}^{1 *}$
}

\begin{abstract}
Background: Non-operative management (NOM) is generally accepted as a treatment method of traumatic paediatric splenic rupture. However, considerable variations in management exist. This study analyses local trends in aetiology and management of paediatric splenic injuries and evaluates the implementation of the guidelines proposed by the American Paediatric Surgical Association (APSA) in a level 1 trauma centre.

Methods: The charts of paediatric patients with blunt splenic injury (BSI) who were admitted or transferred to a level 1 trauma centre between 2003 and 2020 were retrospectively assessed. Information pertaining to demographics, mechanism of injury, injury description, associated injuries, intervention and outcomes were analysed and compared to international literature.
\end{abstract}

Results: There were 130 patients with BSI identified (63.1\% male), with a mean age of $11.3 \pm 4.0$ and a mean Injury Severity Score (ISS) of $21.6 \pm 13.7$. Bicycle accidents were the most common trauma mechanism (23.1\%). Sixty-four percent were multi-trauma patients, $25 \%$ received blood transfusions, and 31\% were haemodynamically unstable. Mean injury grade was 3.0, with 30\% of patients having a high-grade injury. In total, $75 \%$ of patients underwent NOM with a $100 \%$ efficacy rate. Total splenectomy rate was 6.2\%. Four patients died due to brain damage. Patients with a high-grade BSI (grades IV-V) had a significantly higher ISS and longer bedrest and more often presented with an active blush on computed tomography (CT) scans than patients with a low-grade BSI (grades IIII). Non-operative management was mainly the choice of treatment in both groups ( $76.6 \%$ and $79.5 \%$, respectively). Haemodynamic instability was a predictor for operative management $(\mathrm{OM})(p=0.001)$. Predictors for a longer length of stay (LOS) included concomitant injuries, haemodynamic instability and OM (all $p<0.02$ ). Interobserver agreement in the grading of BSI is moderate, with a Cohens Kappa coefficient of 0.493 .

Conclusion: Non-operative management has proven to be a realistic management approach in both low- and high-grade splenic injuries. Consideration for operative management should be based on haemodynamic instability. Compared to the anticipated length of bedrest and hospital stay outlined in the APSA guidelines, the Netherlands can reduce the length of bedrest and hospital stay through their non-operative management.

Level of evidence: Therapeutic study, level III

Keywords: Paediatric, Splenic injury, Trauma, Length of stay

\footnotetext{
* Correspondence: Edward.Tan@radboudumc.nl

${ }^{1}$ Department of Surgery, Radboud University Medical Centre, P.O. Box 9101, 6500, HB, Nijmegen, The Netherlands

Full list of author information is available at the end of the article
}

\section{$\triangle B M C$}

(c) The Author(s). 2021 Open Access This article is licensed under a Creative Commons Attribution 4.0 International License, which permits use, sharing, adaptation, distribution and reproduction in any medium or format, as long as you give appropriate credit to the original author(s) and the source, provide a link to the Creative Commons licence, and indicate if changes were made. The images or other third party material in this article are included in the article's Creative Commons licence, unless indicated otherwise in a credit line to the material. If material is not included in the article's Creative Commons licence and your intended use is not permitted by statutory regulation or exceeds the permitted use, you will need to obtain permission directly from the copyright holder. To view a copy of this licence, visit http://creativecommons.org/licenses/by/4.0/ The Creative Commons Public Domain Dedication waiver (http://creativecommons.org/publicdomain/zero/1.0/) applies to the data made available in this article, unless otherwise stated in a credit line to the data. 


\section{Background}

Trauma is the leading cause of death and disability in children. More than $90 \%$ of the paediatric trauma admissions worldwide are the result of a blunt mechanism, with $10 \%$ of these involving injury to the abdomen and pelvis [1, 2]. The spleen is the most commonly injured intra-abdominal organ in children [2]. Compared to adults, the abdominal organs in children are at a higher risk of organ lesions due to a higher transmission rate of forces through the thinner abdominal wall, larger relative surfaces of the spleen and liver, more flexible ribs and the more horizontal positioning of the diaphragm in children compared to adults [3].

The management of splenic injury in children has evolved since 1968, the year in which Upadhyaya and Simpson introduced non-operative treatment in children with splenic injury [4]. Non-operative management (NOM) has become the standard care for haemodynamically stable patients with blunt splenic injuries without other indications for abdominal surgery. These patients are commonly managed with strict bedrest and close monitoring of vital signs in the hospital. The immediate success of non-operative management at the moment exceeds 95\% [5-7]. Bedrest is also associated with minimal risk for long-term complications, such as secondary haemorrhage and reduction of length of stay without increasing the failure rates of NOM $[6,8]$. However, bedrest has also been associated with complications such as pneumonia [9] (however, this was not seen in our cohort). Furthermore, it reduces the risk of blood utilisation and avoids increased risk of overwhelming post-splenectomy infection (OPSI) in these patients. Although OPSI has a low incidence of $1-4.5 \%$ in the total population (depending on immunologic maturity), it has an exceedingly high mortality rate of 80\% [10-12].

Previous studies conducted in Canada and the USA comparing operative and non-operative management showed great variation in management between hospitals and regions [13-15]. Trauma patient volumes in European centres are often considerably lower than in the USA. Therefore, it is questionable whether these results can be translated to centres with lower volumes of patients with blunt splenic injuries. Variation is also observed within non-operative treatments in Europe [16, 17].

There is currently little data investigating the management and outcomes of paediatric spleen trauma in Europe. This study determines if the internationally accepted guidelines first proposed by Stylianos et al. [18] and the American Paediatric Surgical Association (APSA) committee on non-operative management of traumatic spleen ruptures (both isolated and as part of a multi-trauma) are applicable to the Netherlands. Secondarily, we intend to determine how the outcomes of BSI management in the Netherlands compare to those of foreign hospitals.
The current method of grading splenic injuries in the Netherlands is carried out by a radiologist in the acute trauma setting. Assessment is based on computed tomography scans (CT) made upon admission, and the grades are classified according to the American Association for the Surgery of Trauma (AAST) [19]. This study also investigates interobserver variability in the assessment of injury grades between the initial assessment and the prospective reassessment by a paediatric radiologist.

Although that there are various studies related to nonoperative methods to paediatric spleen injuries in general, there are only a few discussing the successfulness of NOM in patients with severe splenic injury (grades IVV) [20]. Hence, this study investigates if NOM is a feasible treatment option for high-grade splenic injuries.

\section{Methods}

\section{Study design}

This is a retrospective single centre cohort study including paediatric patients younger than 18 years with a diagnosis of BSI. Patients were included when admitted or transferred to our level 1 trauma centre with a specialised paediatric surgical department (Radboudumc) between 1 January 2003 and 1 May 2020. The paediatric age group was defined as age $<18$ years which conforms the age limit for admittance to paediatric hospitals in the Netherlands. Cases meeting the inclusion criteria were identified through the National Trauma Registration (NTR), giving a total study population of 130 patients.

\section{Data collection}

After acquiring institutional review board approval, patient and injury data were collected from electronic hospital charts. Data pertaining to demographics such as age, gender and admission centre were collected. Clinical data obtained included emergency department vital signs, transfusion requirements, Glasgow Coma Scale (GCS), Injury Severity Score (ISS), haemodynamic status, mechanism of injury, splenic injury grade, and other associated injuries. Furthermore, type of management (NOM or operative management $[\mathrm{OM}]$ ), duration of stay in the ward and intensive care unit (ICU), overall length of stay (LOS), period of bedrest, morbidity, mortality, and follow-up were collected. The use of the postsplenectomy protocol was also examined [14], where applicable.

Injury Severity Score was obtained from the NTR. Haemodynamic instability was defined as a systolic blood pressure below $100 \mathrm{mmHg}$, a heart rate above 120 / min, and the need for transfusion [21]. As these parameters differ by age, assessment of the haemodynamic status from the on-call ER physician and trauma surgeon was used. Injury grades were initially classified within 2 days of admission according to the AAST classification 
by the on-call radiologist using the CT scans made upon admission. Injury grades were additionally classified prospectively by a paediatric radiologist using the same CT scans in July 2020. Low-grade splenic injuries were classified as grades I-III, while grades IV and V were categorised as high-grade injuries [20, 22]. Non-operative management was defined as bedrest and monitoring of vital signs, including embolisation of the spleen as it is a less invasive procedure. Operative management was defined as splenectomy, spleen-preserving procedures (including partial splenectomy, splenorrhaphy, and laparotomy only), or an intervention to another organ besides the spleen. All data were collected in an electronic database (Castor Electronic Data Capture, released in 2012). The primary outcome of this study is days of bedrest and overall LOS. Secondary outcome measures are duration of stay in the ward and in the ICU as well as mortality.

\section{Statistical analysis}

Statistical analyses were performed using commercially available software (SPSS, version 25.0; licensed by IBM). Descriptive statistics were generated for each variable and compared with current international literature. Continuous variables are described as mean \pm standard deviation (SD), whereas categorical variables are reported as frequency and percentage $(n, \%)$. Comparisons between groups were performed using the independent $t$ tests or Mann-Whitney $U$ tests for continuous variables and the chi-squared tests and Fisher's exact tests for categorical variables depending on the variables' distribution (which was determined with the Kolmogorov-Smirnov $Z$ test). Independent risk factors for a longer LOS were determined using a multivariate linear regression model. Independent risk factors for operative management (for both the general population and the high-grade injury group) were identified via a multivariable logistic regression analysis. In order to determine inter-observer agreement in injury grading between the initial assessment (in the acute trauma setting) and the additional second assessment (by a paediatric radiologist), the Cohen's kappa coefficient was calculated. All $p$ values were two-sided and were considered statistically significant if $p<0.05$.

\section{Results}

\section{Patient characteristics}

From 2003 to 2020, 130 children were admitted with BSI. Sixty-two patients (47.7\%) were transferred to our hospital, while 68 (52.3\%) arrived from scene. Blunt splenic injury most often occurred during spring (34.6\%). The study population had a median age of 12 years [range 3-17], of whom the majority were male (63.1\%). As presented in Table 1, falls from height were the most common cause of BSI (16.9\%), followed by
Table 1 Characteristics of study population

\begin{tabular}{|c|c|}
\hline \multicolumn{2}{|l|}{ Total study population $(N=130)$} \\
\hline Age in years, median [range] & $12[3-17]$ \\
\hline \multicolumn{2}{|l|}{ Age in years, $N(\%)$} \\
\hline$<6$ years & $13(10.0)$ \\
\hline $6-10$ years & $45(34.6)$ \\
\hline$>10$ years & $72(55.4)$ \\
\hline \multicolumn{2}{|l|}{$\operatorname{Sex}, N(\%)$} \\
\hline Male & $82(63.1)$ \\
\hline Female & $48(36.9)$ \\
\hline \multicolumn{2}{|l|}{ Trauma mechanism, N (\%) } \\
\hline Accidents involving a motorised vehicle & $59(45.4)$ \\
\hline Vehicle-vehicle & $14(10.8)$ \\
\hline Bicycle-vehicle & $21(16.2)$ \\
\hline Pedestrian-vehicle & $10(7.7)$ \\
\hline Single vehicle & $14(10.8)$ \\
\hline Bicycle accidents & $20(15.4)$ \\
\hline Falls & $30(23.1)$ \\
\hline Falls from height (> $1 \mathrm{~m}$ ) & $22(16.9)$ \\
\hline Falls on same level $(<1 \mathrm{~m})$ & $8(6.2)$ \\
\hline Stump object in abdomen & $21(16.2)$ \\
\hline Kick from a horse & $11(8.5)$ \\
\hline Sports/bumping into obstacles & $10(7.7)$ \\
\hline ISS, mean $\pm S D$ & $21.6 \pm 13.7$ \\
\hline \multicolumn{2}{|l|}{ Splenic injury grade, $N(\%)$} \\
\hline Grade I & $11(8.5)$ \\
\hline Grade II & $23(17.7)$ \\
\hline Grade III & $43(33.1)$ \\
\hline Grade IV & $35(26.9)$ \\
\hline Grade V & $4(3.1)$ \\
\hline Undetermined & $14(10.8)$ \\
\hline Presence of active blush on CT, N (\%) & $21(16.2)$ \\
\hline Isolated splenic injury, N (\%) & $47(36.2)$ \\
\hline
\end{tabular}

Abbreviations: CT computerised tomography, ISS Injury Severity Score, SD standard deviation

bicycle-vehicle collisions (16.2\%) and individual bicycle injuries (15.4\%). Those trauma mechanisms preceding BSI were categorised as high-energetic trauma (HET) or low-energetic trauma (LET) in $68.5 \%$ and $31.5 \%$ of cases, respectively. The LET group was mostly represented by individual bicycle accidents (26.8\%). Additional patient demographics of the entire cohort are listed in Table 1.

\section{Injury characteristics}

Nearly $64 \%$ of patients were multi-trauma patients with concomitant injuries. Multi-trauma patients needed to be transfused more often $(30.1 \%$ vs $14.9 \%$ in the isolated injury group; $p=0.037$ ), had a higher ISS ( $26.7 \pm 14.3$ vs 
$12.2 \pm 4.9 ; p<0.001$ ), and were more often haemodynamically unstable $(37.3 \%$ vs $19.1 \%$; $p=0.031)$. Clinical injury data including the distribution of concomitant injuries are presented in Supplementary Table 1. The mean ISS of BSI patients was $21.6 \pm 13.7$. In $20.3 \%$ of cases, GCS was lower than 8, indicating a severely injured neurological state. Mean haemoglobin $(\mathrm{Hb})$ concentration during admission was $7.2 \pm 1.1 \mathrm{mmol} / \mathrm{l}$. Of all patients, $30.8 \%$ were haemodynamically unstable.

They had a significantly higher ISS ( $32.2 \pm 14.6$ vs 17.5 \pm 11.0 in the stable group; $p<0.001$ ) and a lower serum $\mathrm{Hb}$ concentration on admission $(6.2 \pm 1.1$ vs $7.5 \pm 0.9 ; p$ $<0.001)$, leading to more blood transfusions $(77.5 \%$ vs $1.1 \% ; p<0.001$ ), and they more often showed an active blush on CT scan $(22.5 \%$ vs $10.0 \%$; $p=0.006)$. Fifty-nine percent of patients had a low-grade splenic injury (grades I-III) and $30.5 \%$ of patients had a high-grade splenic injury (grades IV-V) based on their CT scan on admission, with a mean splenic injury grade of $3.0( \pm$ 1.0). The distribution in splenic injury grade is presented in Table 1. An active blush was present in $16.2 \%$ of patients. Prior to a CT scan, an abdominal ultrasound was performed for $81.5 \%$ of patients to detect abdominal trauma or free fluid.

\section{Management}

The majority of patients with BSI were treated nonoperatively (74.6\%), including embolisation of the spleen due to haemodynamic instability and the presence of an arterial blush. Of the patients undergoing OM, 24.2\% had a splenectomy, $18.2 \%$ had a spleen-preserving procedure, and $57.6 \%$ experienced an intervention on another organ besides the spleen. Splenectomy rate for the entire cohort was $6.2 \%$. The main reasons for opting for OM were haemodynamic instability (71.4\%), presence of arterial blush (7.1\%), and persistence of abdominal pain (7.1\%). Age and ISS were higher among the OM group than in the NOM group $(12.9 \pm 3.9$ vs $10.8 \pm 4.0 ; p=$ 0.009 and $33.9 \pm 13.5$ vs $17.5 \pm 11.2 ; p<0.001$, respectively). Moreover, patients in the OM group more often needed transfusion $(45.5 \%$ vs $17.5 \%$; $p<0.001)$ and were haemodynamically unstable more frequently $(66.7 \%$ vs $18.6 \% ; p<0.001$ ), and all were multi-trauma patients due to a HET $(p<0.001)$. Multivariable logistic regression analysis shows that being haemodynamically unstable is an independent predictor for OM (odds ratio [OR] 0.151 [95\% confidence interval (CI) $0.05-0.45$ ]; $p=$ $0.001)$.

The post-splenectomy protocol was followed by $75.0 \%$ of patients who underwent splenectomy and $40.0 \%$ of those who underwent embolisation. They all received pneumococcal vaccinations and in some cases additional influenza and meningococcal vaccinations. Eighty-nine percent of our cohort received pain medication, consisting most often of paracetamol (84.9\%) or opioids (64.2\%). Follow-up after BSI mostly consisted of clinical check-ups $(25.7 \%)$ that were sometimes combined with secondary ultrasound of the spleen (13.3\%). Follow-up time varied from 1 to 8 weeks, with an average of 3 weeks. After discharge, doctors advised a return to activities within 7 weeks in $77.0 \%$ of cases. This was extended to $>7$ weeks for multi-trauma or operated patients.

\section{Treatment outcomes}

The main treatment outcomes of BSI are displayed in Table 2. One-hundred-and-three patients (79.2\%) were admitted to the ICU during admission. After bedrest, initialisation of mobilisation/ambulation was delayed with a mean of $5.3 \pm 3.5$ days. The duration of stay in the ward, duration of stay in the ICU, and LOS were significantly higher $(p<0.01)$ in patients that were either haemodynamically unstable, multi-trauma patients or managed operatively. The amount of bedrest was significantly higher $(p<0.03)$ in both unstable patients and when undergoing OM.

According to the multivariate linear regression analysis, independent predictors for an extended LOS are OM (unstandardised regression coefficient $[\beta] 6.98[95 \%$ CI 2.98-10.98]; $p=0.001)$, unstable haemodynamics $([\beta]$ 4.97 [95\% CI 1.46-8.48]; $p=0.006$ ) and presence of concomitant injuries $([\beta] 4.80$ [95\% CI 8.59-1.01]; $p=$ $0.014)$. These predictors explain a significant part of the variance in LOS (adjusted $R$-squared $=0.311 ; F(6,109)=$ 9.664; $p<0.001$ ). Patients had a longer LOS of 7.0 days when managed operatively, 5.0 days when they were haemodynamically unstable and 4.8 days when they were multi-trauma patients.

Although no complications related to splenic injury occurred, $20.0 \%$ endured complications from another origin. Most often these were neurological or psychiatric complications (34.6\% and $50.0 \%$, respectively) due to multi-trauma. Four patients (3.1\%) died within 10 days of admission due to non-survivable brain damage. They were multi-trauma patients with an ISS exceeding 50.

A comparison of the clinical data and outcomes of management between low-grade and high-grade splenic injuries is depicted in Table 3.

\section{Differences between OM and NOM in patients with a high-grade BSI}

Of the patients with a high-grade splenic injury $(n=$ 39), 79.5\% underwent NOM. Five of these patients were treated with embolisation, due to haemodynamic instability or the presence of an active blush on their CT scan. Of those managed operatively (20.5\%), three had a splenectomy (37.5\%), one underwent a laparotomy $(12.5 \%)$ and one had a spleen-preserving procedure $(12.5 \%)$. 
Table 2 Treatment outcomes for blunt splenic injuries

\begin{tabular}{llll}
\hline Treatment outcomes: Mean \pm SD [range] & Total & High-grade & Low-grade \\
\hline Length of ward stay (in days) & $6.8 \pm 5.9[0-24]$ & $6.5 \pm 4.8[0-24]$ & $6.6 \pm 6.4[0-24]$ \\
Length of ICU stay (in days) & $3.5 \pm 5.6[0-30]$ & $3.8 \pm 5.5[0-30]$ & $3.5 \pm 6.0[0-29]$ \\
LOS (in days) & $10.2 \pm 9.0[1-43]$ & $10.1 \pm 8.0[1-39]$ & $10.2 \pm 9.7[2-43]$ \\
Bedrest (in days) & $5.0 \pm 3.1[0-16]$ & $5.5 \pm 2.6[2-16]$ & $4.8 \pm 3.3[0-14]$ \\
Splenic complications & & No splenic complications & \\
In-hospital mortality (\% of all patients) & 3.1 & 2.6 & 1.3 \\
\hline
\end{tabular}

Abbreviations: ICU intensive care unit, LOS length of stay, SD standard deviation

A comparison of the clinical data and outcomes of management for the NOM and OM groups for patients with a high-grade splenic injury is depicted in Table 4 . Patients who were treated operatively were significantly older (15.6 \pm 1.8 vs $10.6 \pm 3.7 ; p<0.001)$, had a higher ISS $(43.7 \pm 7.1$ vs $20.2 \pm 7.9 ; p<0.001)$ and had an extended LOS $(16.1 \pm 10.9$ vs $8.5 \pm 6.4 ; p=0.013)$. Similarly, operatively treated patients were all multi-trauma patients due to a HET ( $p=0.003$ and $p=0.042$, respectively). The multivariable logistic regression analysis shows that age is an independent predictor for OM (OR 0.855 [95\% CI 0.75-0.97]; $p=0.015)$.

\section{Interobserver variability}

The difference in injury grades, as determined by the radiologist in the acute trauma setting and reassessed by

Table 3 Comparison of characteristics: low-grade vs high-grade splenic injuries

\begin{tabular}{|c|c|c|c|}
\hline & Low-grade $(N=77)$ & High-grade $(N=39)$ & $P$ value \\
\hline Age (in years) & $11.0 \pm 4.0$ & $11.6 \pm 4.0$ & $0.359^{c}$ \\
\hline Male (\%) & 62.3 & 66.7 & $0.647^{\mathrm{a}}$ \\
\hline Serum $\mathrm{Hb}$ (in mmol/l) & $7.5 \pm 1.0$ & $6.6 \pm 1.2$ & $0.005^{c}$ \\
\hline Need of blood transfusion (\%) & 18.2 & 35.9 & $0.047^{\mathrm{a}}$ \\
\hline ISS (in points) & 19.4 & 24.4 & $0.022^{c}$ \\
\hline Trauma mechanism that occurred most (\%) & Bicycle vs vehicle accident (19.5) & Bicycle accident (20.5) & $0.960^{\mathrm{b}}$ \\
\hline LET (\%) & 32.5 & 30.8 & $0.853^{\mathrm{a}}$ \\
\hline HET (\%) & 67.5 & 69.2 & $0.853^{\mathrm{a}}$ \\
\hline Presence of active blush (\%) & 9.1 & 30.8 & $0.002^{\mathrm{a}}$ \\
\hline \multicolumn{4}{|l|}{ Haemodynamic stability } \\
\hline Stable (\%) & 76.6 & 64.1 & $0.154^{a}$ \\
\hline Unstable (\%) & 23.4 & 35.9 & \\
\hline Isolated splenic injury (\%) & 32.5 & 48.7 & $0.088^{a}$ \\
\hline \multicolumn{4}{|l|}{ Management } \\
\hline NOM (\%) & 76.6 & 79.5 & $0.727^{a}$ \\
\hline OM (\%) & 23.4 & 20.5 & $0.727^{\mathrm{a}}$ \\
\hline Embolisation (\%) & 0.0 & 12.8 & $0.004^{b}$ \\
\hline Splenectomy (\%) & 2.6 & 7.7 & $0.333^{b}$ \\
\hline Stay in ward (in days) & $6.6 \pm 6.4$ & $6.5 \pm 4.8$ & $0.134^{c}$ \\
\hline Stay in ICU (in days) & $3.5 \pm 6.0$ & $3.8 \pm 5.5$ & $0.160^{c}$ \\
\hline LOS (in days) & $10.2 \pm 9.7$ & $10.1 \pm 8.0$ & $0.058^{c}$ \\
\hline Bedrest (in days) & $4.8 \pm 3.3$ & $5.5 \pm 2.6$ & $0.004^{c}$ \\
\hline Mortality (\%) & 1.3 & 2.6 & $0.561^{b}$ \\
\hline
\end{tabular}

Bold parameters are significant (as $P$ value $<0.05$ )

Abbreviations: $H b$ haemoglobin, HET high-energetic trauma, ICU intensive care unit, ISS Injury Severity Score, LET low-energetic trauma, LOS length of stay, NOM non-operative management, $O M$ operative management

${ }^{\mathrm{a} C h i}$-squared test

${ }^{b}$ Fisher's exact test

cMann-Whitney $U$ test 
Table 4 Comparison of characteristics: NOM vs OM in patients with high-grade splenic injury

\begin{tabular}{|c|c|c|c|}
\hline & Non-operative $(N=31)$ & Operative $(N=8)$ & $P$ value \\
\hline Age (in years) & $10.6 \pm 3.7$ & $15.6 \pm 1.8$ & $0.000^{b}$ \\
\hline Male (\%) & 64.5 & 75.0 & $0.694^{\mathrm{a}}$ \\
\hline Serum $\mathrm{Hb}$ (in $\mathrm{mmol} / \mathrm{l})$ & $6.7 \pm 1.2$ & $6.3 \pm 1.6$ & $0.223^{c}$ \\
\hline Need of blood transfusion (\%) & 32.3 & 50.0 & $0.424^{\mathrm{a}}$ \\
\hline ISS (in points) & $20.2 \pm 7.9$ & $43.7 \pm 7.1$ & $0.000^{b}$ \\
\hline Trauma mechanism that occurred most (\%) & Bicycle accident (22.6) & Vehicle vs vehicle accident (37.5) & $0.223^{\mathrm{a}}$ \\
\hline LET (\%) & 38.7 & 0.0 & $0.042^{\mathrm{a}}$ \\
\hline HET (\%) & 61.3 & 100.0 & \\
\hline Presence of active blush (\%) & 29.6 & 50.0 & $0.402^{\mathrm{a}}$ \\
\hline \multicolumn{4}{|l|}{ Haemodynamic stability } \\
\hline Stable (\%) & 71.0 & 37.5 & $0.109^{a}$ \\
\hline Unstable (\%) & 29.0 & 62.5 & $0.109^{\mathrm{a}}$ \\
\hline Isolated splenic injury (\%) & 61.3 & 0.0 & $0.003^{\mathrm{a}}$ \\
\hline Stay in ward (in days) & $5.8 \pm 3.8$ & $8.9 \pm 7.4$ & $0.150^{\mathrm{b}}$ \\
\hline Stay in ICU (in days) & $2.9 \pm 3.4$ & $7.3 \pm 10.0$ & $0.184^{b}$ \\
\hline LOS (in days) & $8.5 \pm 6.4$ & $16.1 \pm 10.9$ & $0.013^{b}$ \\
\hline Bedrest (in days) & $5.4 \pm 2.3$ & $6.5 \pm 4.4$ & $0.932^{b}$ \\
\hline Mortality (\%) & 0.0 & 12.5 & $0.205^{\mathrm{a}}$ \\
\hline
\end{tabular}

Bold parameters are significant (as $P$ value $<0.05$ )

Abbreviations: $H b$ haemoglobin, HET high-energetic trauma, ICU intensive care unit, ISS Injury Severity Score, LET low-energetic trauma, LOS length of stay ${ }^{\text {a}}$ Fisher's exact test

${ }^{\mathrm{b}}$ Mann-Whitney $U$ test

'Independent sample $t$ test

a paediatric radiologist, is presented in Table 5. Blunt splenic injuries tend to be graded higher in the acute trauma setting, with a mean injury grade of $3.0 \pm 1.10$, as compared to reassessment by a paediatric radiologist, with a mean injury grade of $2.7 \pm 1.37$. However, this difference was not significant $(p=0.519)$. The Cohens Kappa coefficient was 0.493 , indicating that interobserver agreement is moderate.

Furthermore, presence of an active injury on a CT scan in the acute trauma setting was detected

Table 5 Interobserver variability: initial vs rescored injury grade

\begin{tabular}{lllllllll}
\hline & Grade & \multicolumn{2}{l}{ Rescored $^{\mathbf{b}}$} & & Total \\
\cline { 3 - 7 } & & $\mathbf{0}$ & $\mathbf{I}$ & $\mathbf{~ I}$ & III & IV & V & \\
\hline Initial $^{\text {a }}$ & $\mathbf{0}$ & 0 & 0 & 0 & 0 & 0 & 0 & 0 \\
& I & 2 & 6 & 2 & 0 & 0 & 0 & 10 \\
& II & 0 & 1 & 15 & 3 & 0 & 0 & 19 \\
& III & 1 & 0 & 7 & 26 & 7 & 0 & 41 \\
& IV & 0 & 0 & 1 & 13 & 17 & 1 & 32 \\
& V & 0 & 0 & 0 & 0 & 1 & 3 & 4 \\
Total & & 3 & 7 & 25 & 42 & 25 & 4 & 106
\end{tabular}

${ }^{a}$ Initial grading (based on the AAST score) was performed in the acute trauma setting by the radiologists on call

bProspective rescoring of injury grades was done by Karin Kamphuis-van

Ulzen, a paediatric radiologist at Radboudumc Nijmegen significantly more often than during reassessment $(16.2 \%$ vs $10.0 \% ; p<0.001)$.

\section{Discussion}

This study shows that non-operative management is still the best management option for patients with splenic injuries that are haemodynamically stable. However, operative treatment may be necessary, especially in patients who are haemodynamically unstable, which is usually apparent on admission or within $12 \mathrm{~h}$ of injury [18, 23]. In accordance with the bedrest and hospitalisation periods deemed safe by the APSA guidelines, shorter periods of bedrest can be applied in our hospital as per the results of this study.

\section{Management}

This study shows no crossover between initial NOM to OM regardless of injury grade, thus giving a $100 \%$ success rate for NOM for both low-grade and high-grade splenic injuries; this is better than international splenic salvage rates reaching a maximum of $99 \%$ for isolated injuries in the last 30 years [24]. Non-operative treatment has proven to be associated with minimal risk of shortand long-term complications such as haemorrhages, abscesses, pseudo-aneurysms and (pseudo-) cysts. In our cohort, no splenic complications occurred during the 
follow-up time of a maximum of 8 weeks. Managing a paediatric patient non-operatively spares the additional risk of overwhelming infections associated with asplenic patients and gives them better quality of life measurements compared to those who undergo splenectomy [12, 25-27].

The success of NOM increases with splenic artery embolisation even in high-grade injuries in 3.8\% of cases (all high-grade BSI). Recent research in the paediatric population shows that embolisation can be a viable alternative to splenectomy when non-operative treatment fails [28]. It has been demonstrated that immune function after splenic artery embolisation is similar to patients who have not been embolised [28, 29]. Splenic artery embolisation has been possible since 2009 in our hospital; as such this treatment option was not accessible to a portion of our cohort.

A relatively low percentage of patients who underwent a splenectomy (6.2\%) was found in relation to comparable international studies [1, 13, 20, 30-38] (Supplementary Table 3 ) and studies performed in the Netherlands, in which $17.4 \%$ and $21.3 \%$ of patients underwent a splenectomy, respectively [16, 39]. This study supports that unstable haemodynamics is an independent risk factor for splenectomy in children [5], possibly in combination with the presence of an active blush on the CT scan. Post-splenectomy protocol has also altered in recent years, and now post-operative vaccination is routinely implemented.

\section{APSA guidelines}

The actual duration of stay in the ICU and total length of stay for isolated splenic injuries treated with NOM compared to the APSA guidelines are presented in Supplementary Table 2 . As shown in the table, ICU stay and LOS in our hospital are almost equal to the guidelines. Even though the current protocol has been implemented since 2006, its implementation is still an ongoing process. This study observed a mean stay at the hospital of $5.6 \pm 2.1$ days in isolated splenic injuries and $7.7 \pm 6.8$ days in conservatively treated patients. Related studies in the Netherlands show higher lengths for hospital stay (11.9 \pm 5.2 days and 7-16 days after 2000) $[16,39]$. This study shows that the length of stay is shorter than in other related studies in the Netherlands. Thus, our results suggest that the APSA guidelines are safe and applicable to the Dutch context and that our hospital can apply a shorter period of bedrest and hospitalisation for children with splenic injuries.

\section{Grading splenic injury}

This study addresses an unstudied practice: the prospective assessment of the injury grade of splenic injuries based on CT scans. Review of current literature on the grading of splenic injury using CT scans and predicting the optimal management of BSI shows differing opinions regarding whether injury grade is a determinant of splenectomy [40-42]. After rescoring all available CT scans, moderate agreement was found between the initial radiologist in the acute trauma setting and the paediatric-radiologist in the research setting. In other words, slight overscoring of splenic injuries occurred in the acute trauma setting. One could argue that in the acute trauma setting a radiologist is more prone to 'upscale' the grading as there is sometimes limited time and the radiologist is not specialised in paediatric trauma. However, no evidence was found to support this theory. It is important to do further research on how to improve the correctness of agreement on the scoring of splenic injuries because different scores could possibly change the management decision and therefore the length of hospitalisation [43]. For this reason, we recommend a specialised paediatric radiologist to be available for the emergency department at all times to reassess the CT scans during admission or to help assess the CT scan before management is determined.

\section{Dutch-specific aetiology}

This study describes a Dutch-specific aetiology in splenic injuries. Studies performed in the Netherlands showed data supporting the contribution of motor vehicle accidents (45.4\%), falls (23.1\%) and bicycle accidents (15.4\%) to splenic injury [16]. An interesting difference between this study and studies performed internationally is that a higher percentage of bicycle accidents occurred as the trauma mechanism for BSI in the Netherlands (see Supplementary Table 3) [31, 35-38]. This difference in aetiology can be explained by the fact that in the Netherlands (and in the UK as well), the bicycle is an important means of transportation for adults and children alike. Similar findings on aetiology were found in paediatric pancreatic trauma [44].

\section{Limitations}

The present study has several limitations. First, this study is susceptible to the limitations that come with all retrospective studies using national administrative databases, namely missing data due to inaccurate recordkeeping. As our study only uses the electronic hospital charts from our hospital, we could not obtain long-term patient outcomes and complications after patients were transferred. In the future, meticulous record keeping can result in more complete studies in this particular field. Nevertheless, our clinic is representative of the Netherlands as a paediatric trauma clinic and our management is coordinated with the Dutch Association for Paediatric Surgery. Our research demonstrates that nonoperative management can be chosen regardless of injury grade. In addition, we identified independent 
predictors for operative management and a longer length of stay.

This study covers a long time period for admissions (stretching over 17 years) in which much has changed in the management of paediatric splenic injuries. In the earlier years, there was an inclination towards $\mathrm{OM}$ of high-grade injuries $(28.6 \%$ before the implementation of embolisation in 2009 vs $18.7 \%$ after implementation; $p=$ 0.617). Presently, a paradigm shift can be observed in that patients with a high-grade splenic injury who are haemodynamically stable are sometimes treated conservatively. The APSA guidelines have clear recommendations concerning splenic injuries of grades I to IV. However, recent literature about therapy on grade $\mathrm{V}$ splenic injuries is rare. This study supports the strategy to initially choose NOM in all high-grade injuries as the majority of patients (almost $80.0 \%$ ) are successfully managed conservatively, with a $100 \%$ accuracy rate. Indeed, this percentage is an underestimation given that $37.5 \%$ of the patients in the high-grade group who were managed operatively needed surgery for an injury other than their splenic rupture. Even though NOM might be possible as the initial treatment in some cases, the decision between NOM and OM depends on careful risk-benefit analysis for each patient, particularly taking into account haemodynamic status and the expertise of the surgeon and the multidisciplinary hospital team. More recent evidence suggests that for higher grade injuries angioembolisation may also be suitable as an adjunct to NOM if the patient becomes haemodynamically unstable [45-49]. In our hospital, this technique has been available for children since 2009.

A striking observation of differences in age limit occurs when looking at Supplementary Table 3. In all studies, only paediatric patients with BSI were included. However, a diverse variation in the definition of 'paediatric' is used, ranging from $<16$ years to $<22$ years of age. Hence, comparisons between studies should be performed cautiously.

Moreover, the study conducted is a single-institution study, which creates a small sample size, and therefore, the results might not be generalisable to the Dutch population. To allow better comparison with international study outcomes, a nationwide study with all level I trauma centres in the Netherlands would be the next logical step in future studies. Though sample size is relatively small, the scarce number of publications considering NOM in high-grade splenic injuries and the proven success of NOM enhances the significance of our study. The treatment protocol used in our hospital is in accordance with national paediatric trauma guidelines.

\section{Conclusion}

To our knowledge, studies documenting the aetiology, management and outcome of BSI in children in Europe and the Netherlands are scarce. In paediatric blunt splenic trauma, NOM is the treatment of choice in haemodynamically stable children regardless of injury grade. Few complications are observed following this method of management. Our advice is to follow the APSA guidelines more effectively by reducing hospital admissions. Initial grading of splenic injuries is initially overestimated, though the decision in management of BSI still depends on haemodynamic status, meaning that overscoring of injury grade does not influence management.

\section{Supplementary Information}

The online version contains supplementary material available at https://doi. org/10.1186/s13017-021-00353-4

Additional file 1: Supplementary Table 1: Distribution of

concomitant injuries

Additional file 2: Supplementary Table 2: Proposed APSA guidelines vs actual treatment

Additional file 3: Supplementary Table 3: International Comparable Studies

\section{Abbreviations}

AAST: American Association for the Surgery of Trauma; APSA: American Paediatric Surgical Association; $\beta$ : Unstandardised regression coefficient; BSI: Blunt splenic injury; Cl: Confidence interval; CT: Computed tomography; NOM: Non-operative management; GCS: Glasgow Coma Scale;

Hb: Haemoglobin; HET: High-energetic trauma; ICU: Intensive care unit; ISS: Injury Severity Score; LET: Low-energetic trauma; LOS: Length of stay; N: Number; NTR: National Trauma Registration; OM: Operative management; OPSI: Overwhelming post-splenectomy infection; OR: Odds ratio;

SD: Standard deviation; SPA: Splenic pseudo-aneurysms; US: United States

\section{Acknowledgements}

The authors would like to acknowledge the administrative staff at Radboud University Medical Centre for their valuable contribution to this work.

\section{Authors' contributions}

Study conception and design: DL, ET, IB, MG. Data acquisition: DL, KK, MG. Analysis and data interpretation: MG. Secondary grading splenic injuries: KK. Drafting of manuscript: MG Critical revision: DL, ET, IB, MG. The authors read and approved the final manuscript.

Funding

Not applicable.

\section{Availability of data and materials}

The datasets used and/or analysed during the current study are available from the corresponding author on reasonable request.

\section{Ethics approval and consent to participate}

This study has been reviewed by the ethics committee on the basis of the Dutch Code of conduct for health research, the Dutch Code of conduct for responsible use, the Dutch Personal Data Protection Act and the Medical

Treatment Agreement Act. The ethics committee passed a positive judgement on the study.

Consent for publication Not applicable.

Competing interests

The authors declare no competing interests. 


\section{Author details}

'Department of Surgery, Radboud University Medical Centre, P.O. Box 9101, 6500, HB, Nijmegen, The Netherlands. ${ }^{2}$ Department of Orthopaedic Surgery, Radboud University Medical Centre, P.O. Box 9101, 6500, HB, Nijmegen, The Netherlands. ${ }^{3}$ Department of Radiology, Radboud University Medical Centre P.O. Box 9101, 6500, HB, Nijmegen, The Netherlands. ${ }^{4}$ Department of Paediatric Surgery, Radboud University Medical Centre, P.O. Box 9101, 6500, HB, Nijmegen, The Netherlands.

\section{Received: 12 January 2021 Accepted: 16 February 2021}

\section{Published online: 27 February 2021}

\section{References}

1. Dodgion CM, Gosain A, Rogers A, St Peter SD, Nichol PF, Ostlie DJ. National trends in pediatric blunt spleen and liver injury management and potential benefits of an abbreviated bed rest protocol. J Pediatr Surg. 2014;49(6):10041008; discussion 8

2. Gaines BA. Intra-abdominal solid organ injury in children: diagnosis and treatment. J Trauma. 2009;67(2 Suppl):S135-9.

3. Klimek PM, Lutz T, Stranzinger E, Zachariou Z, Kessler U, Berger S. Handlebar injuries in children. Pediatr Surg Int. 2013;29(3):269-73.

4. Upadhyaya P, Simpson JS. Splenic trauma in children. Surg Gynecol Obstet. 1968;126(4):781-90.

5. Fick AEA, Raychaudhuri P, Bear J, Roy G, Balogh Z, Kumar R. Factors predicting the need for splenectomy in children with blunt splenic trauma. ANZ J Surg. 2011:81(10):717-9.

6. Kristoffersen KW, Mooney DP. Long-term outcome of nonoperative pediatric splenic injury management. J Pediatr Surg. 2007:42(6):1038-1041; discussion 41-2.

7. Mooney DP, Forbes PW. Variation in the management of pediatric splenic injuries in New England. J Trauma. 2004;56(2):328-33.

8. Haan J, llahi ON, Kramer M, Scalea TM, Myers J. Protocol-driven nonoperative management in patients with blunt splenic trauma and minimal associated injury decreases length of stay. J Trauma. 2003;55(2):317321; discussion 21-2

9. Teasell R, Dittmer DK. Complications of immobilization and bed rest. Part 2: Other complications. Can Fam Phys. 1993:39:1440-2 5-6.

10. Hansen K, Singer DB. Asplenic-hyposplenic overwhelming sepsis: postsplenectomy sepsis revisited. Pediatr Dev Pathol. 2001;4(2):105-21.

11. Partrick DA, Bensard DD, Moore EE, Karrer FM. Nonoperative management of solid organ injuries in children results in decreased blood utilization. J Pediatr Surg. 1999;34(11):1695-9.

12. Waghorn DJ. Overwhelming infection in asplenic patients: current best practice preventive measures are not being followed. J Clin Pathol. 2001; 54(3):214-8

13. Hsiao M, Sathya C, de Mestral C, Langer JC, Gomez D, Nathens AB. Population-based analysis of blunt splenic injury management in children: Operative rate is an informative quality of care indicator. Injury-Int J Care Inj. 2014;45(5):859-63.

14. McDonald LA, Yanchar NL. Management of pediatric splenic injuries in Canada. J Pediatr Surg. 2012;47(3):473-6.

15. Mooney DP, Rothstein DH, Forbes PW. Variation in the management of pediatric splenic injuries in the United States. J Trauma. 2006;61(2):330-3 discussion 3.

16. De Jong WJ, Nellensteijn DR, Ten Duis HJ, Albers MJ, Moumni ME, Hulscher JB. Blunt splenic trauma in children: are we too careful? Eur J Pediatr Surg. 2011;21(4):234-7.

17. Dobremez E, Lefevre Y, Harper L, Rebouissoux L, Lavrand F, Bondonny JM, et al. Complications occurring during conservative management of splenic trauma in children. Eur J Pediatr Surg. 2006;16(3):166-70.

18. Stylianos S. Evidence-based guidelines for resource utilization in children with isolated spleen or liver injury. The APSA Trauma Committee. J Pediatr Surg. 2000;35(2):164-167; discussion 7-9.

19. Moore EE, Cogbill TH, Jurkovich GJ, Shackford SR, Malangoni MA, Champion HR. Organ injury scaling: spleen and liver (1994 Revision). J Trauma Acute Care Surg. 1995;38(3):323-4.

20. Karadeniz Cerit K, Ergelen R, Abdullayev T, Tugtepe H, Dagli TE, Kiyan G. The effectiveness of non-operative treatment in high-grade liver and spleen injury in children. Ulus Travma Acil Cerrahi Derg. 2018;24(6):569-74.

21. Subbe CP, Kruger M, Rutherford P, Gemmel L. Validation of a modified Early Warning Score in medical admissions. Qjm. 2001;94(10):521-6.
22. Alamri Y, Moon D, Yen DA, Wakeman C, Eglinton T, Frizelle F. Ten-year experience of splenic trauma in New Zealand: the rise of non-operative management. N Z Med J. 2017;130(1463):11-8.

23. Thompson SR, Holland AJ. Evolution of non-operative management for blunt splenic trauma in children. J Paediatr Child Health. 2006;42(5):231-4.

24. Davies DA, Pearl RH, Ein SH, Langer JC, Wales PW. Management of blunt splenic injury in children: evolution of the nonoperative approach. J Pediatr Surg. 2009;44(5):1005-8.

25. Chaikof EL, McCabe CJ. Fatal overwhelming postsplenectomy infection. Am Surg. 1985;149(4):534-9.

26. Jenks PJ, Jones E. Infections in asplenic patients. Clin Microbiol Infect. 1996; 1(4):266-72.

27. Melles DC, de Marie S. Prevention of infections in hyposplenic and asplenic patients: an update. Neth J Med. 2004;62(2):45-52.

28. Gross JL, Woll NL, Hanson CA, Pohl C, Scorpio RJ, Kennedy AP Jr, et al. Embolization for pediatric blunt splenic injury is an alternative to splenectomy when observation fails. J Trauma Acute Care Surg. 2013;75(3): 421-5.

29. Malhotra AK, Carter RF, Lebman DA, Carter DS, Riaz OJ, Aboutanos MB, et al. Preservation of splenic immunocompetence after splenic artery angioembolization for blunt splenic injury. J Trauma. 2010;69(5):1126-1130; discussion 30-1.

30. Lee J, Moriarty KP, Tashjian DB. Less is more: management of pediatric splenic injury. Arch Surg. 2012;147(5):437-41.

31. Mitchell RJ, Curtis K, Chong S, Holland AJA, Soundappan SVS, Wilson KL, et al. Comparative analysis of trends in paediatric trauma outcomes in New South Wales, Australia. Injury. 2013;44(1):97-103.

32. Bairdain S, Litman HJ, Troy M, McMahon M, Almodovar H, Zurakowski D, et al. Twenty-years of splenic preservation at a level 1 pediatric trauma center. J Pediatr Surg. 2015;50(5):864-8.

33. Kim KH, Kim JS, Kim WW. Outcome of children with blunt liver or spleen injuries: Experience from a single institution in Korea. Int J Surg. 2017;38: 105-8.

34. Yang K, Li Y, Wang C, Xiang B, Chen S, Ji Y. Clinical features and outcomes of blunt splenic injury in children: a retrospective study in a single institution in China. Medicine. 2017:96(51):e9419.

35. Adams SE, Holland A, Brown J. A comparison of the management of blunt splenic injury in children and young people-a New South Wales, population-based, retrospective study. Injury Int J Care Inj. 2018;49(1):42-50.

36. Alexander M, Zaghal A, Wetjen K, Shelton J, Shilyansky J. Pediatric trauma center verification improves quality of care and reduces resource utilization in blunt splenic injury. J Pediatr Surg. 2019;54(1):155-9.

37. Ardley R, Carone L, Smith S, Spreadborough S, Davies P, Brooks A. Blunt splenic injury in children: haemodynamic status key to guiding management, a 5-year review of practice in a UK major trauma centre. Eur $J$ Trauma Emerg Surg. 2019;45(5):791-9.

38. Teuben M, Spijkerman R, Teuber H, Pfeifer R, Pape HC, Kramer W, et al. Splenic injury severity, not admission hemodynamics, predicts need for surgery in pediatric blunt splenic trauma. Pat Saf Surg. 2020;14(1):8.

39. Veger HT, Jukema GN, Bode PJ. Pediatric splenic injury: nonoperative management first! Eur J Trauma Emerg Surg. 2008;34(3):267-72.

40. Lynn KN, Werder GM, Callaghan RM, Sullivan AN, Jafri ZH, Bloom DA. Pediatric blunt splenic trauma: a comprehensive review. Pediatr Radiol. 2009:39(9):904-16 quiz 1029-30.

41. Potoka DA, Schall LC, Ford HR. Risk factors for splenectomy in children with blunt splenic trauma. J Pediatr Surg. 2002;37(3):294-9.

42. Davies DA, Ein SH, Pearl R, Langer JC, Traubici J, Mikrogianakis A, et al. What is the significance of contrast "blush" in pediatric blunt splenic trauma? J Pediatr Surg. 2010;45(5):916-20.

43. Leschied JR, Mazza MB, Davenport MS, Chong ST, Smith EA, Hoff CN, et al. Inter-radiologist agreement for $\mathrm{CT}$ scoring of pediatric splenic injuries and effect on an established clinical practice guideline. Pediatr Radiol. 2016; 46(2):229-36.

44. de Blaauw I, Winkelhorst JT, Rieu PN, van der Staak FH, Wijnen MH, Severijnen RS, et al. Pancreatic injury in children: good outcome of nonoperative treatment. J Pediatr Surg. 2008:43(9):1640-3.

45. Banerjee A, Duane TM, Wilson SP, Haney S, O'Neill PJ, Evans HL, et al. Trauma center variation in splenic artery embolization and spleen salvage: a multicenter analysis. J Trauma Acute Care Surg. 2013;75(1):69-74; discussion -5.

46. Haan JM, Biffl W, Knudson MM, Davis KA, Oka T, Majercik S, et al. Splenic embolization revisited: a multicenter review. J Trauma. 2004;56(3):542-7. 
47. Jeremitsky E, Kao A, Carlton C, Rodriguez A, Ong A. Does splenic embolization and grade of splenic injury impact nonoperative management in patients sustaining blunt splenic trauma? Am Surg. 2011;77(2):215-20.

48. Liu PP, Lee WC, Cheng YF, Hsieh PM, Hsieh YM, Tan BL, et al. Use of splenic artery embolization as an adjunct to nonsurgical management of blunt splenic injury. J Trauma. 2004;56(4):768-772; discussion 73.

49. Wei B, Hemmila MR, Arbabi S, Taheri PA, Wahl WL. Angioembolization reduces operative intervention for blunt splenic injury. J Trauma. 2008;64(6): $1472-7$.

\section{Publisher's Note}

Springer Nature remains neutral with regard to jurisdictional claims in published maps and institutional affiliations.

Ready to submit your research? Choose BMC and benefit from:

- fast, convenient online submission

- thorough peer review by experienced researchers in your field

- rapid publication on acceptance

- support for research data, including large and complex data types

- gold Open Access which fosters wider collaboration and increased citations

- maximum visibility for your research: over $100 \mathrm{M}$ website views per year

At BMC, research is always in progress.

Learn more biomedcentral.com/submissions 